\title{
Enriching protein-protein and functional interaction networks in human embryonic stem cells
}

\author{
CHANGQING ZUO $^{1}$, SHUANG LIANG ${ }^{1}$, ZONGGUI WANG $^{2}$, HUA LI $^{1}$, WENLING ZHENG $^{3}$ and WENLI MA ${ }^{1}$ \\ ${ }^{1}$ Institute of Genetic Engineering, Southern Medical University, Guangzhou, Guangdong 510515; \\ ${ }^{2}$ Department of Biochemistry and Molecular Biology, Guangdong Medical College, Dongguan, Guangdong 523808; \\ ${ }^{3}$ Southern China Genomics Reseach Center, Guangzhou, Guangdong 510800, P.R. China
}

Received January 16, 2009; Accepted March 6, 2009

DOI: 10.3892/ijmm_00000197

\begin{abstract}
Human Embryonic Stem Cells (hESCs) have a great therapeutic potential in regenerative medicine, but the precise molecular mechanisms by which hESCs maintain or regulate their characteristics remain largely unknown. Since protein-protein interaction is vitally important in regulating hESCs, we utilized a network-based bioinformatics analysis in order to learn what and how specific proteins interact with each other. By combining protein-protein interaction data and a collection of genes over-expressed in hESCs, we constructed a protein interaction network using a breadth-first search algorithm. This scale-free network which is significantly larger than networks generated by random samplings, illustrates how these hESC-enriched proteins might interact with each other in hESCs. Of the top 5\% highly connected nodes (corresponding to 21 proteins including MYC, H2AFX, RUVBL1, DDX18, CDC2, HDAC2 and HIST1H4C) presumably critical for determining the fate of hESCs, nearly half are known to be regulated by NANOG/SOX2/MYC. This underscores importance of these transcription factors in hESCs. In addition, in silico cis-element analysis suggests that NF-Y may be an important transcription factor regulating many of these hub proteins (high connected nodes) in hESCs. To further abstract the functional significance, directly connected proteins were matched to and grouped by gene ontology (GO) terms in molecular function category. Sixtysix interacting GO-GO terms paired through protein interactions were found over-represented in hESCs. This functional enrichment may be essential for understanding molecular characteristics in hESCs. Collectively, we analyzed hESCenriched genes based on protein-protein interaction data, from which an hESC-enriched protein interaction network was constructed and a network of molecular functional terms was also identified. The results of this analysis, on the systems
\end{abstract}

Correspondence to: Dr Wenli Ma, Institute of Genetic Engineering, Southern Medical University, Guangzhou, Guangdong 510515, P.R. China

E-mail: wenli668@gmail.com

Key words: scare-free network, bioinformatics, protein interaction, gene ontology, embryonic stem cell level, may shed new light to further our understanding of hESCs.

\section{Introduction}

Human Embryonic Stem Cells (hESCs) are pluripotent cells isolated from the inner cell mass of the blastocyst (1). They can differentiate into all tissue types in vivo, and into the three primary germ layers as well as extra-embryonic tissues in vitro. Because of these unique characteristics, these cells are potentially invaluable in regenerative medicine (2-5). Efforts on this have identified some important genes in hESC lines, such as OCT3/4, NANOG, REX1, SOX2 and FOXD3 (6-10). However, our knowledge concerning the many characteristics of hESCs is still limited. One main reason may be that the vast majority of studies have focused on individual genes/proteins, without considering the possible role of interactions. It is well known that most proteins do not function in isolation, but rather interact with one another to form molecular networks, and larger protein complexes are, in turn, part of a more extensive biological web.

With the evolution of high-throughput technologies in the post-genomics era, studies have shifted from characterization of single protein to investigation of the entire interactome. Nowadays, biological knowledge is often represented by networks, such as regulatory and metabolic networks. Construction and analyses of these networks have revealed interesting characteristics within the framework of interactome. For example, hub proteins in networks tend to be more conserved $(11,12)$. There are an increasing number of studies focusing on the transcriptional networks, which emphasize the roles of transcription factors, in regulating human ES cells. As a result, a number of important transcription factors responsible for self-renewal and pluripotency have been identified (13-16). In recent years, the networkbased approach has gained popularity and been successfully applied for analysis of protein-protein interaction networks in many species and diseases (17-19). For instance, one study using affinity purification of NANOG under native conditions followed by mass spectrometry generated a mouse ES protein interaction network including only 37 proteins (20). However, the picture is far from complete.

Microarray technology provides us a unique opportunity to examine gene expression patterns in hESCs. However, 
heterogeneity of hESCs gene expression data could exist across different laboratories or different cell lines, which could be partly circumvented by meta-analysis to give a more robust result. A 'consensus hESCs gene list' was produced (21), and some of the genes on the list are also expressed in certain other tissues. The authors explain that these proteins may not be highly specific to hESCs individually, however, they act together with other proteins to function specifically in hESCs (21). Based on these observations, we postulate that there may be an enriched protein interaction subnetwork(s) among a collection of those on or off the list to maintain or to modify properties of hESCs.

In this study, two questions were raised: i) Do the hESCenriched genes/proteins interact directly with each other more frequently than expected by chance alone? In other words, does an hESC-enriched protein interaction network exist at all? ii) Can any enriched functional interaction patterns be identified to be important for maintaining characteristics of hESCs? To address these questions, we performed networkbased analysis of both enriched genes/proteins and ontological terms to propose the existence of an hESC-enriched molecular interaction network.

\section{Materials and methods}

Gene list. We collected genes over-expressed in hESCs in at least 3 independent studies, re-affirmed by a meta-analysis of human embryonic stem cells transcriptome - Amazonia (http://amazonia.montp.inserm.fr/) (21). We only collected those with known entrez gene id from the original 'consensus hESC gene list' called by the authors. The resulting list includes 1029 unique gene ids. We converted these gene ids to 1020 UniProtKB/Swiss-Prot accession numbers using UniProt ID mapping (http://www.uniprot.org/jobs) and named them hESC enriched proteins (hESPs).

Protein-protein interaction data. To obtain protein-protein interaction data, we downloaded the i2d database for human (http://ophid.utoronto.ca/ophidv2.201/) (12), which contains a new release of the Online Predicted Human Interaction Database (OPHID), and human protein-protein interactome assembled from other databases complemented by homolog interactions identified in other organisms (22). It now includes 138554 protein interaction pairs for 13560 proteins in UniProtKB/Swiss-Prot. We wrote a Perl script to remove reciprocally redundant pairs (for example: proteins $\mathrm{A}$ and $\mathrm{B}$ can form pairs A-B and B-A with one of them removed). We obtained 92545 unique protein interaction pairs (UPI). To the best of our knowledge, this is perhaps the largest protein interaction network for humans.

Tissue specificity/selectivity. Tissue-specific/selective gene expression is believed to be of physiological importance (23). To verify whether hESC-enriched genes are tissue-specific/ selective or not, we compared them with 3904 tissue-selective genes surveying 97 tissue types (stem cell and other related tissue or cell types not surveyed) (24).

Network construction and analysis. Network for hESPs was constructed using a Perl script (named Max Network Program,
MNP). The program took as input human protein-protein interaction data downloaded from the i2d database, and mapped interaction of hESPs within the entire protein-protein interaction network using a breadth-first search algorithm. The resulting subnet, named as Max Network Protein Interaction Pairs or MNPIP, was visually rendered by Cytoscape program (http://www.cytoscape.org/) (25). To assess the significance of MNPIP, 1000 simulations were done with equal number of input proteins randomly selected. The free statistical package R (http://www.r-project.org/) was used to compute Wilcoxon signed rank test statistics for difference between MNPIP and sub-networks randomly generated, with a $\mathrm{p}<0.05$ considered as significant.

Hub analysis. We classified nodes in the network according to the degree of connectivity. The top 5\% of the most connected proteins in this network were regarded as hubs. Promoter sequence (from 1200 bp upstream to $200 \mathrm{bp}$ downstream of the transcription start site, TSS) analysis was done using Gather (http://gather.genome.duke.edu/) and TFM-Explorer (http://bioinfo.lifl.fr/TFME/).

Enriched functional interaction pairs and network. Interacting partners are likely to be functionally related. To identify functional enrichment in hESCs, we assigned GOSlim function terms to human UiprotKB/Swiss-Prot proteins in i2d database whenever possible. A total of 42 GOSlim function terms from QuickGO (www.ebi.ac.uk/ego) were used. Proteins assigned with the same GOSlim term were considered functionally similar. One protein could have multiple GOSlim assignments if it is involved in various functional aspects. Based on the underlying protein-protein interactions, pairs of interacting GOSlim terms were formed to represent interacting functional groups. This was done with the help of a Perl script (named Interaction Patterns Analysis or IPA). We calculated an enrichment score for each GOSlim-GOSlim interaction pair originated from all human interacting proteins in i2d database or from hESC-enriched proteins. We based our enrichment score on EASE, a modified Fisher Exact p-value used by DAVID (http://david.abcc.ncifcrf.gov/home.jsp) (26).

\section{Results}

Tissue specificity/selectivity. Previous study has generated 3904 tissue-selective unique protein-coding genes (from the latest Affymetrix annotation, express in 5 or less human tissues) for 97 normal human tissue types (24). When comparing 1029 hESC-enriched genes (see Materials and methods) with the tissue-selective ones, 274 genes (Fig. 1) were found intersected. This suggests that some of the hESCenriched genes are not strictly specific to hESCs, which is not uncommon as described (21).

Protein interaction network for enriched genes. Previous studies have suggested that hESC-enriched proteins (hESPs) may act in a cooperative manner rather than in isolation. In this study, we found evidence to support this. First, out of the $1020 \mathrm{hESPs}$ (see Materials and methods), 784 proteins were found in i2d interaction database, which formed 1765 binary protein interaction pairs (BPIP). With 1000 random samplings 


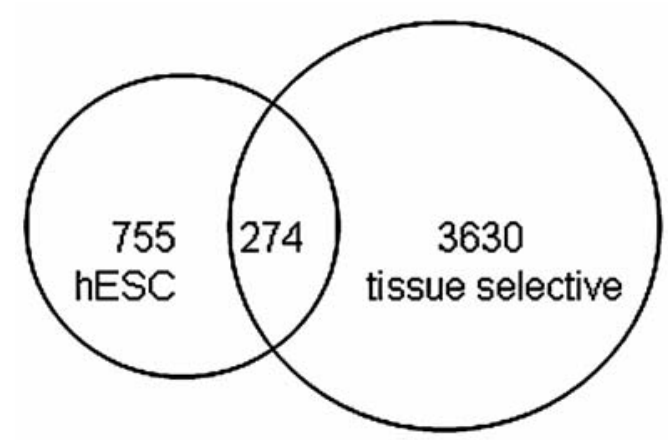

Figure 1. Venn diagrams of the hESC-enriched genes and tissue selective genes. of the same size (i.e. 784 random proteins) from all nonredundant proteins recorded in i2d database, significantly less BPIP were found $(484 \pm 50$ BPIP, $\mathrm{p}<2.2 \mathrm{e}-16$, estimated by one-sided Wilcoxon signed rank test with continuity correction). Next, we searched for the most dense subnetwork consisting of interacting hESPs. Remarkably, a significant fraction of the interacting hESPs (403 out of 784 proteins, $51.4 \%$ ) forms a large subnetwork connecting each other. However, 1000 random samplings of 784 proteins from i2d yielded significant smaller subnetworks consisting of $8.5-33.3 \%$ of input proteins (as compared to $51.4 \%$ for hESPs, $\mathrm{p}<2.2 \mathrm{e}-16$, one-sided Wilcoxon signed rank test with continuity correction, Table I). Thus, the above results

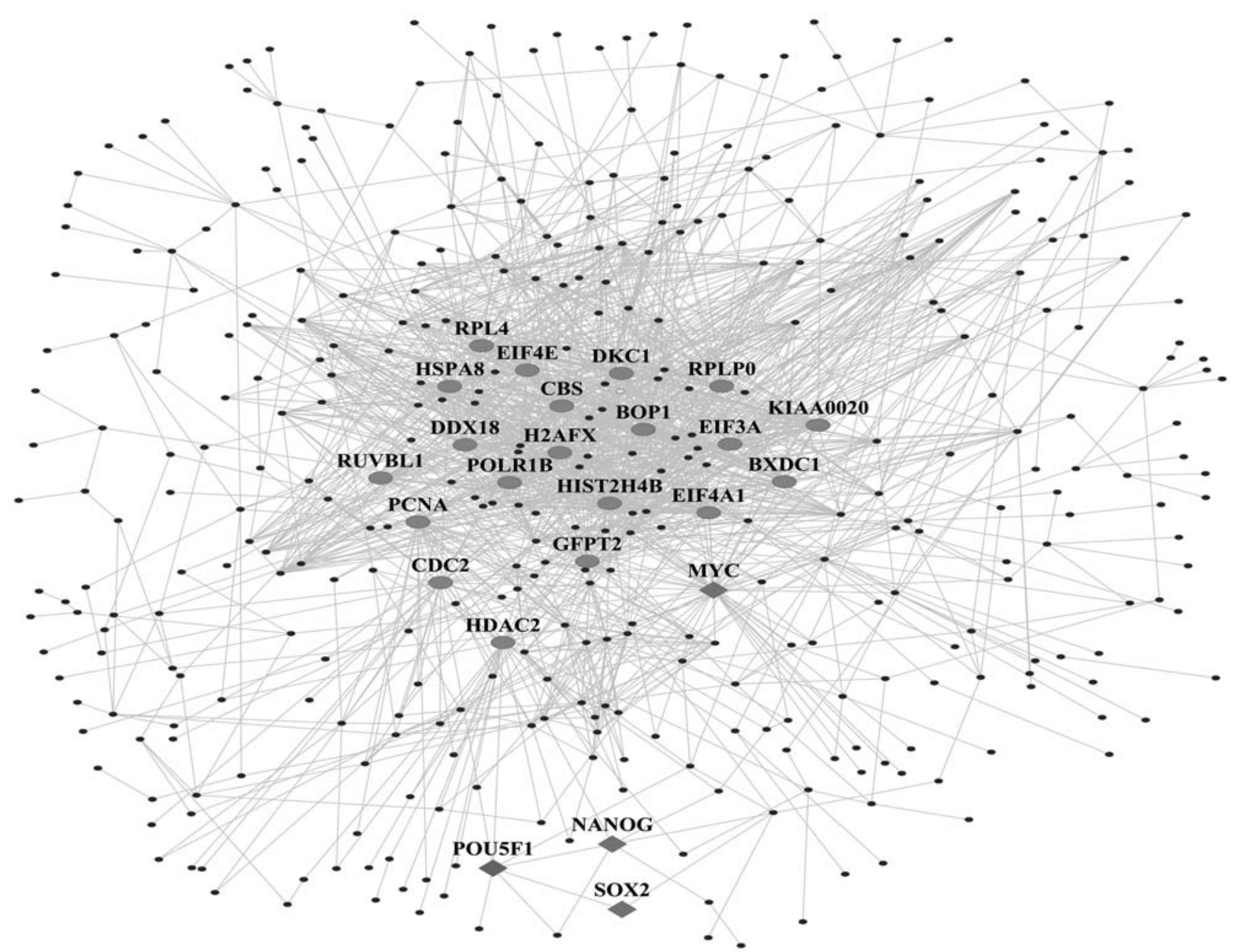

Figure 2. The hESC-enriched protein interaction network. Twenty hubs are labelled and shown as ovals and 4 known important transcription factors in the network are shown as diamonds (MYC is both a hub and a transription factor).

Table I. Significant analysis of BPIP and MNN using hESPs and randomly selected proteins.

\begin{tabular}{lccc}
\hline & hESCs & Random & P-value $^{\mathrm{a}}$ \\
\hline Number of binary protein interaction pairs (BPIP) & 1765 & $484 \pm 50$ & $\mathrm{P}<2.2 \mathrm{e}-16$ \\
Number of max network nodes (MNN) & 403 & $179 \pm 32$ & $\mathrm{P}<2.2 \mathrm{e}-16$ \\
\hline
\end{tabular}

${ }^{\mathrm{a} O n e-s i d e d ~ W i l c o x o n ~ s i g n e d ~ r a n k ~ t e s t ~ w i t h ~ c o n t i n u i t y ~ c o r r e c t i o n . ~}$ 


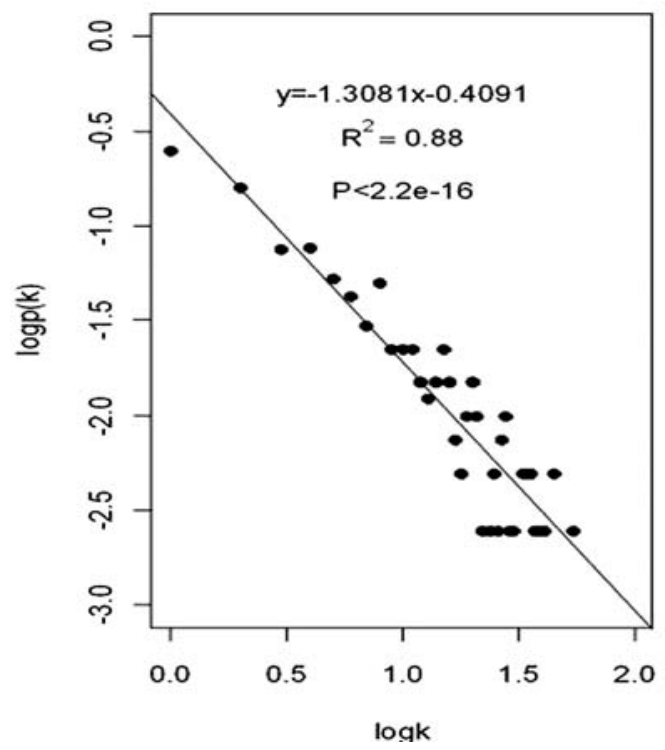

Figure 3. The $\log$ plot of $\mathrm{P}(\mathrm{k})$ against $\mathrm{k}$ illustrating scale-free characteristics $(\gamma=1.3081)$ of $\mathrm{hESC}$-enriched protein interaction network $\left(\mathrm{P}(\mathrm{k}) \sim \mathrm{k}^{-\gamma}\right)$. The plot was generated using the free software R. indicate that a significant portion of the hESPs may cooperate directly or indirectly by means of interaction to form the hESC-enriched protein interaction network (Fig. 2).

Hubs analysis of hESC-enriched protein interaction network. Most biological networks follow power law distribution, $\mathrm{P}(\mathrm{K}) \sim \mathrm{K}^{-\gamma}$ according to the Barabasi-Albert model (27). A network with $\gamma<3$ is a typical scale-free network which possesses a small number of highly connected nodes/hubs in contact with a large number of nodes of low connectivity. The hESC-enriched protein interaction network $(\gamma=1.3081$, Fig. 3) in which a few hubs are heavily connected with most nodes of low connectivity, is a scale-free network by definition. Since it is hard to draw a line as to what a hub is, we focused on the top $5 \%$ most connected nodes in the network and called them hubs. This accounts for a total of 21 nodes (Table II), each of which having more than 28 partners.

Some of the transcription factors identified previously, e.g. OCT4, SOX2, NANOG and c-MYC, are very important for generating induced Pluripotent Stem (iPS) cells, and therefore are believed to be important regulators for hESCs

Table II. List of 21 hubs in hESC-enriched protein interaction network.

\begin{tabular}{|c|c|c|c|c|}
\hline $\begin{array}{l}\text { Swiss-Prot } \\
\text { Accession }\end{array}$ & Gene symbol & $\begin{array}{l}\text { NANOG/SOX2/ } \\
\text { MYC target }^{\mathrm{a}}\end{array}$ & $\begin{array}{l}\text { Involvement in } \\
\text { cancer }^{b}\end{array}$ & $\begin{array}{l}\text { Biocarta pathwayc } \\
\text { (part of cell growth) }\end{array}$ \\
\hline P62805 & HIST1H4C & $\mathrm{B}, \mathrm{C}$ & - & - \\
\hline P01106 & MYC & - & $\mathrm{Y}$ & $\begin{array}{l}\text { MAPKinase/p38 MAPK/WNT } \\
\text { signaling pathway }\end{array}$ \\
\hline P60842 & EIF4A1 & A & $\mathrm{Y}$ & $\begin{array}{c}\text { Internal bibosome entry pathway } \\
\text { mTOR signaling pathway }\end{array}$ \\
\hline Q9NVP1 & DDX18 & B & $\mathrm{Y}$ & - \\
\hline P16104 & $\mathrm{H} 2 \mathrm{AFX}$ & $\mathrm{B}, \mathrm{C}$ & $\mathrm{Y}$ & - \\
\hline Q15397 & KIAA0020 & - & - & - \\
\hline P36578 & RPL4 & - & - & - \\
\hline P12004 & PCNA & B & $\mathrm{Y}$ & p53 signaling pathway \\
\hline Q9H9Y6 & POLR1B & - & - & - \\
\hline P11142 & HSPA8 & A & $\mathrm{Y}$ & - \\
\hline O60832 & DKC1 & A & $\mathrm{Y}$ & - \\
\hline P06493 & $\mathrm{CDC} 2$ & $\mathrm{~B}, \mathrm{C}$ & $\mathrm{Y}$ & Cyclins and cell cycle regulation \\
\hline P06730 & EIF4E & A & $\mathrm{Y}$ & $\begin{array}{c}\text { Internal ribosome entry pathway } \\
\text { mTOR signaling pathway }\end{array}$ \\
\hline Q9H7B2 & BXDC1 & - & - & - \\
\hline Q14137 & BOP1 & - & $\mathrm{Y}$ & - \\
\hline P05388 & RPLP0 & - & $\mathrm{Y}$ & - \\
\hline Q14152 & EIF3A & - & $\mathrm{Y}$ & - \\
\hline Q9Y265 & RUVBL1 & - & $\mathrm{Y}$ & - \\
\hline Q92769 & HDAC2 & $\mathrm{C}$ & $\mathrm{Y}$ & $\begin{array}{l}\text { Mechanisms of transcriptional } \\
\text { repression by DNA methylation }\end{array}$ \\
\hline O94808 & GFPT2 & - & - & - \\
\hline P35520 & CBS & A & - & - \\
\hline
\end{tabular}

${ }^{\mathrm{a}} \mathrm{A}$, targets of MYC; B, targets of NANOG; C, targets of SOX2. ${ }^{\mathrm{b}} \mathrm{Y}$, involvement in cancer from current knowledge. ${ }^{\mathrm{c}} \mathrm{http} / / / \mathrm{www} . \mathrm{biocarta} . c 0 m /$ genes/index.asp. 
Table III. List of molecular function-GO-GO term interaction pairs enriched in human embryonic stem cells.

\begin{tabular}{|c|c|c|c|c|}
\hline GO term 1 & GO term 2 & GO term 1 function & $\mathrm{GO}$ term 2 function & EASE score \\
\hline GO:0003677 & GO:0016787 & DNA binding & Hydrolase activity & $3.3 e-46$ \\
\hline GO:0000166 & GO:0003677 & Nucleotide binding & DNA binding & $7.9 \mathrm{e}-40$ \\
\hline GO:0003677 & GO:0005515 & DNA binding & Protein binding & $1.5 e-36$ \\
\hline GO:0005515 & GO:0016787 & Protein binding & Hydrolase activity & $8.4 \mathrm{e}-26$ \\
\hline GO:0003677 & GO:0003824 & DNA binding & Catalytic activity & $2.7 e-24$ \\
\hline GO:0000166 & GO:0000166 & Nucleotide binding & Nucleotide binding & $4.4 e-23$ \\
\hline GO:0003723 & GO:0005515 & RNA binding & Protein binding & $4.8 \mathrm{e}-17$ \\
\hline GO:0003824 & GO:0005515 & Catalytic activity & Protein binding & $5.6 e-17$ \\
\hline GO:0000166 & GO:0016787 & Nucleotide binding & Hydrolase activity & $3.2 \mathrm{e}-16$ \\
\hline GO:0000166 & GO:0005515 & Nucleotide binding & Protein binding & $4.9 \mathrm{e}-16$ \\
\hline GO:0003824 & GO:0016787 & Catalytic activity & Hydrolase activity & $1.2 \mathrm{e}-14$ \\
\hline GO:0005515 & GO:0005515 & Protein binding & Protein binding & $2.1 \mathrm{e}-14$ \\
\hline GO:0003723 & GO:0016787 & RNA binding & Hydrolase activity & $5.0 \mathrm{e}-14$ \\
\hline GO:0003824 & GO:0003824 & Catalytic activity & Catalytic activity & $2.6 e-13$ \\
\hline GO:0016787 & GO:0016787 & Hydrolase activity & Hydrolase activity & $3.6 e-12$ \\
\hline GO:0003723 & GO:0003723 & RNA binding & RNA binding & $4.9 \mathrm{e}-12$ \\
\hline GO:0004518 & GO:0005515 & Nuclease activity & Protein binding & $9.9 \mathrm{e}-09$ \\
\hline GO:0003723 & GO:0003824 & RNA binding & Catalytic activity & $2.5 \mathrm{e}-07$ \\
\hline GO:0004518 & GO:0004518 & Nuclease activity & Nuclease activity & $3.4 \mathrm{e}-07$ \\
\hline GO:0005515 & GO:0008135 & Protein binding & $\begin{array}{l}\text { Translation factor activity, } \\
\text { nucleic acid binding }\end{array}$ & $2.2 \mathrm{e}-6$ \\
\hline GO:0005488 & GO:0016787 & Binding & Hydrolase activity & $2.4 \mathrm{e}-6$ \\
\hline GO:0004518 & GO:0016787 & Nuclease activity & Hydrolase activity & $3.7 e-6$ \\
\hline GO:0003677 & GO:0005215 & DNA binding & Transporter activity & $5.9 \mathrm{e}-6$ \\
\hline GO:0003677 & GO:0016740 & DNA binding & Transferase activity & $9.0 \mathrm{e}-6$ \\
\hline GO:0003824 & GO:0004518 & Catalytic activity & Nuclease activity & $1.0 \mathrm{e}-5$ \\
\hline GO:0003723 & GO:0009055 & RNA binding & Electron carrier activity & $1.6 e-5$ \\
\hline GO:0003676 & GO:0003677 & Nucleic acid binding & DNA binding & $2.1 e-5$ \\
\hline GO:0016740 & GO:0016787 & Transferase activity & Hydrolase activity & $4.6 e-5$ \\
\hline GO:0003723 & GO:0008135 & RNA binding & $\begin{array}{l}\text { Translation factor activity, } \\
\text { nucleic acid binding }\end{array}$ & $6.9 e-5$ \\
\hline GO:0003677 & GO:0004518 & DNA binding & Nuclease activity & $6.7 e-5$ \\
\hline GO:0003824 & GO:0008135 & Catalytic activity & $\begin{array}{l}\text { Translation factor activity, } \\
\text { nucleic acid binding }\end{array}$ & $1.4 \mathrm{e}-4$ \\
\hline GO:0000166 & GO:0008135 & Nucleotide binding & $\begin{array}{l}\text { Translation factor activity, } \\
\text { nucleic acid binding }\end{array}$ & $1.9 \mathrm{e}-4$ \\
\hline GO:0000166 & GO:0004518 & Nucleotide binding & Nuclease activity & $2.3 \mathrm{e}-4$ \\
\hline GO:0003723 & GO:0004518 & RNA binding & Nuclease activity & $3.0 \mathrm{e}-4$ \\
\hline GO:0003677 & GO:0005488 & DNA binding & Binding & $4.1 \mathrm{e}-4$ \\
\hline GO:0008135 & GO:0016787 & $\begin{array}{l}\text { Translation factor } \\
\text { activity, nucleic } \\
\text { acid binding }\end{array}$ & Hydrolase activity & $4.8 \mathrm{e}-4$ \\
\hline GO:0003682 & GO:0005515 & Chromatin binding & Protein binding & $4.8 \mathrm{e}-4$ \\
\hline GO:0000166 & GO:0003676 & Nucleotide binding & Nucleic acid binding & $5.0 \mathrm{e}-4$ \\
\hline GO:0003677 & GO:0003682 & DNA binding & Chromatin binding & $6.6 e-4$ \\
\hline GO:0003824 & GO:0016740 & Catalytic activity & Transferase activity & $7.5 \mathrm{e}-4$ \\
\hline GO:0003682 & GO:0016787 & Chromatin binding & Hydrolase activity & 0.002 \\
\hline GO:0000166 & GO:0016740 & Nucleotide binding & Transferase activity & 0.002 \\
\hline GO:0003676 & GO:0016787 & Nucleic acid binding & Hydrolase activity & 0.002 \\
\hline GO:0003676 & GO:0003723 & Nucleic acid binding & RNA binding & 0.002 \\
\hline
\end{tabular}


Table III. Continued.

\begin{tabular}{|c|c|c|c|c|}
\hline GO term 1 & GO term 2 & GO term1 function & GO term 2 function & EASE score \\
\hline GO:0003677 & GO:0005198 & DNA binding & Structural molecule activity & 0.005 \\
\hline GO:0030234 & GO:0030234 & $\begin{array}{l}\text { Enzyme regulator } \\
\text { activity }\end{array}$ & Enzyme regulator activity & 0.006 \\
\hline GO:0003676 & GO:0005515 & Nucleic acid binding & Protein binding & 0.006 \\
\hline GO:0000166 & GO:0003682 & Nucleotide binding & Chromatin binding & 0.007 \\
\hline GO:0003677 & GO:0008135 & DNA binding & $\begin{array}{l}\text { Translation factor activity, } \\
\text { nucleic acid binding }\end{array}$ & 0.007 \\
\hline GO:0008135 & GO:0009055 & $\begin{array}{l}\text { Translation factor } \\
\text { activity,nucleic } \\
\text { acid binding }\end{array}$ & Electron carrier activity & 0.007 \\
\hline GO:0003723 & GO:0005488 & RNA binding & Binding & 0.007 \\
\hline GO:0003824 & GO:0005488 & Catalytic activity & Binding & 0.008 \\
\hline GO:0003676 & GO:0003824 & Nucleic acid binding & Catalytic activity & 0.010 \\
\hline GO:0005488 & GO:0008135 & Binding & $\begin{array}{l}\text { Translation factor activity, } \\
\text { nucleic acid binding }\end{array}$ & 0.011 \\
\hline GO:0003677 & GO:0016301 & DNA binding & Kinase activity & 0.012 \\
\hline GO:0004518 & GO:0016301 & Nuclease activity & Kinase activity & 0.014 \\
\hline GO:0016740 & GO:0016740 & Transferase activity & Transferase activity & 0.015 \\
\hline GO:0005198 & GO:0005215 & $\begin{array}{l}\text { Structural molecule } \\
\text { activity }\end{array}$ & Transporter activity & 0.016 \\
\hline GO:0005198 & GO:0009055 & $\begin{array}{l}\text { Structural molecule } \\
\text { activity }\end{array}$ & Electron carrier activity & 0.016 \\
\hline GO:0003723 & GO:0016740 & RNA binding & Transferase activity & 0.017 \\
\hline GO:0003824 & GO:0004721 & Catalytic activity & $\begin{array}{l}\text { Phosphoprotein phosphatase } \\
\text { activity }\end{array}$ & 0.017 \\
\hline GO:0003700 & GO:0016787 & $\begin{array}{l}\text { Transcription factor } \\
\text { activity }\end{array}$ & Hydrolase activity & 0.018 \\
\hline GO:0003723 & GO:0004721 & RNA binding & $\begin{array}{l}\text { Phosphoprotein } \\
\text { phosphatase activity }\end{array}$ & 0.020 \\
\hline GO:0003676 & GO:0008135 & Nucleic acid binding & $\begin{array}{l}\text { Translation factor activity, } \\
\text { nucleic acid binding }\end{array}$ & 0.023 \\
\hline GO:0003676 & GO:0003676 & Nucleic acid binding & Nucleic acid binding & 0.030 \\
\hline GO:0008135 & GO:0008135 & $\begin{array}{l}\text { Translation factor } \\
\text { activity, nucleic acid } \\
\text { binding }\end{array}$ & $\begin{array}{l}\text { Translation factor activity, } \\
\text { nucleic acid binding }\end{array}$ & 0.030 \\
\hline
\end{tabular}

$(6,7,9,28,29)$. In the hESC-enriched protein interaction network, transcription of many hub protein-coding genes were regulated by these transcription factors $(30,31)$ (Table II). Interestingly, nearly half of the hub proteins are known to be involved in tumorigenesis or associated with poor cancer prognosis (32-45) (Table II). Among the top 10-ranked transcription factor binding sites predicted by both Gather and TFM explorer, those for transcription factor NF-Y were found in common within the proximal promoter sequences of nine hub protein-coding genes.

Enriched functional interactions. Cellular behavior is a consequence of the complex interactions between its numerous constituents. To gain more biological insights by studying functional interactions, we first annotated each protein in the hESC-enriched protein protein interaction pairs with a subset of Gene Ontology terms. In this study, 42 GOSlim terms from the molecular function category of the Gene Ontology were used. Our goal was to identify significantly enriched functionally interacting GO-GO pairs. This resulted in 66 GO-GO interaction pairs (Table III) enriched in hESCs. Except for GO:0030234, most of them were found in a functionally interacting network (Fig. 4). The top four most connected GOSlim terms in this network are: GO:0003677, GO:0016787, GO:0003723 and GO:0003824.

\section{Discussion}

We studied the interactions of a list of genes over-expressed in hESCs. A protein-protein interaction subnetwork formed 


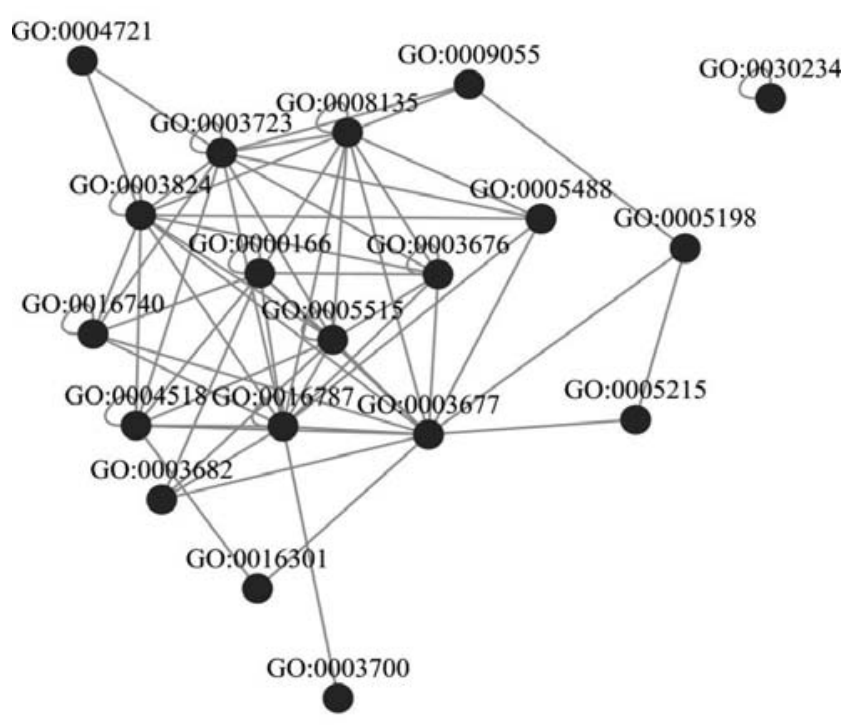

Figure 4. Enriched 'GOSlim-GOSlim interaction' network in hESC (molecular function interaction patterns).

with a significant number of hESC-enriched genes was identified by integrating gene expression and protein interaction data. It is full of hESC-enriched genes and is very likely to be responsible for maintaining characteristics of hESCs. This scale-free network has a few dominant hubs heavily connected with most nodes of low connectivity. A series of studies have shown that hub proteins in a scale-free network are likely to be essential for growth and the degree of connectivity correlates with other phenotypes in addition to essentiality (46-48). Scale-free networks, albeit more tolerant to random removal of nodes, are vulnerable to loss of highly interactive hubs (49).

MYC, one of the hubs in our hESC-enriched protein interaction network, is a key factor for inducing Pluripotent Stem (iPS) cells (29), and for regulating self-renewal and pluripotency in mouse ES cells (mESCs) (50). A recent study showed that $\mathrm{H} 2 \mathrm{AFX} / \mathrm{H} 2 \mathrm{AX}$, also a hub in the hESC-enriched protein interaction network, participates in a critical signaling pathway different from that of somatic cells to control stem cell proliferation (51). RUVBL1/TIP49a, an important hub identified in this study and a common hub in co-expression networks found in both hESCs and mESCs (52), plays a critical role in c-MYC and WNT signaling pathways $(32,53)$. RUVBL1/TIP49a was also found to be evolutionarily highly conserved and essential for viability in yeast, flies and worms (54). Furthermore, WNT, mTOR and MAPK pathways are pivotal for regulating hESCs, as evidenced by the involvement of several hub proteins in these pathways (55-57). We anticipate that some other hubs or nodes identified in this study may turn out to be important factors in future investigations of hESCs.

To our surprise, several important transcription factors, namely NANOG, SOX2, OCT4, are not among the most connected hubs in this network whereas some of their targets are (Table II). These factors also share some common targets (30), which suggests that they work closely in a regulatory network. In addition, OCT4 interacts with NANOG and SOX2 in the hESC-enriched protein interaction network.

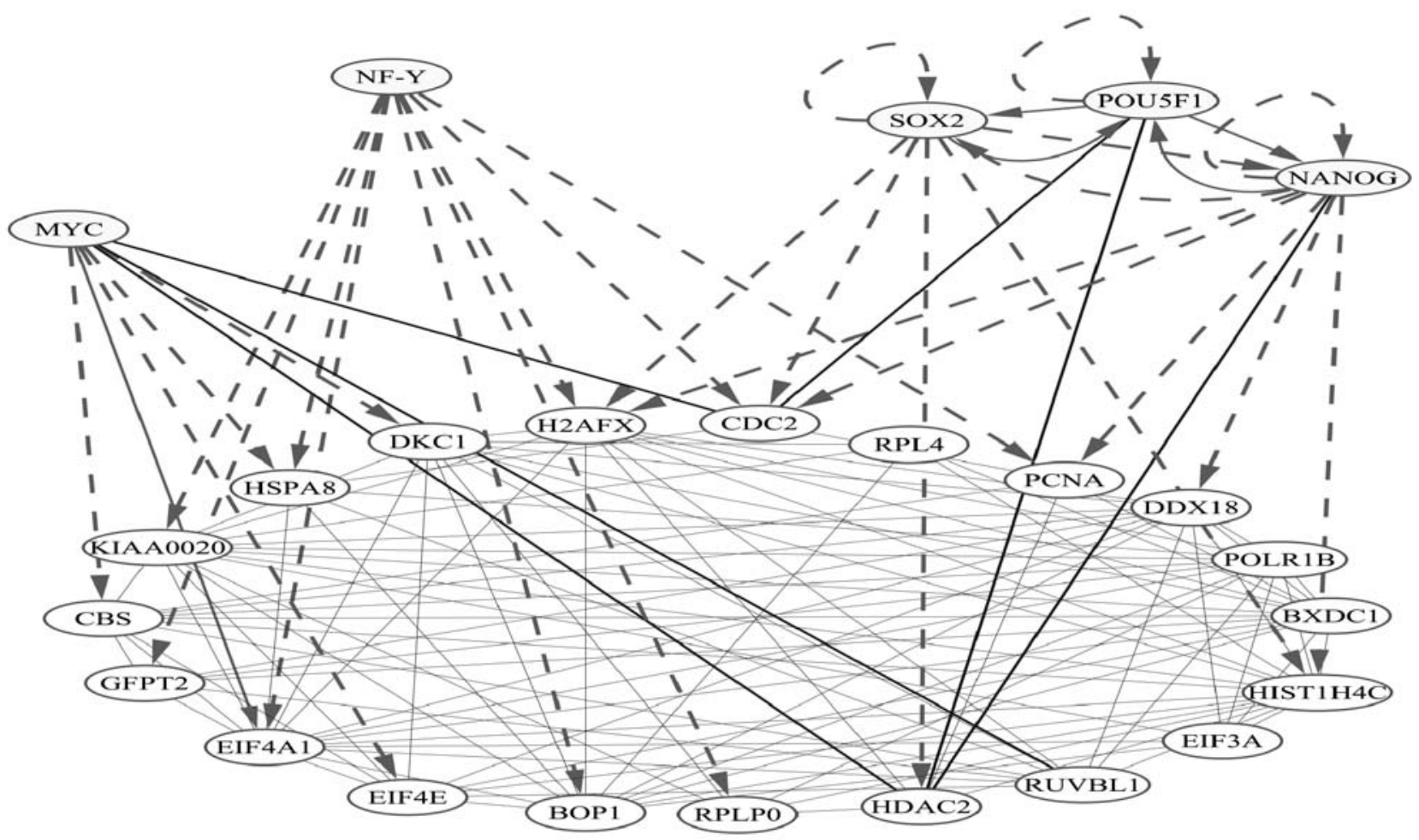

Figure 5. The relationship between hubs and important transcription factors in hESC-enriched protein interaction network: solid line, protein-protein interaction; solid line with arrows, protein-protein interactions with regulatory potential and direction (as indicated by arrows) and dash line with arrows, with regulatory potential and direction only. Important transcription factors (SOX2, POU5F1, NANOG, MYC and NF-Y), their targets (ovals) and regulatory circuits (arrows) are indicated. 
Regulatory circuits formed by some of these factors and their targets, as reported previously based on experimental findings (20), may be used to fine-tune characteristics of the ES. Furthermore, the directed or self-directed regulatory loops of OCT4, NANOG and SOX2 can be used to maintain proper and stable expression level (30) through a robust synergistic and sustained network topology (through regulation of many hubs) whose stabilization is vitally important for hESC (Fig. 5). Any imbalance of a regulator with its targets or with itself in the network may produce unexpected outcomes. This also suggests that synergistic hubs target activation by their regulators is a very important mechanism by which these tran-scription factors, albeit not hubs, control self-renewal and pluripotency in hESCs.

In addition to the above important transcription factors, NF-Y was predicted by in silico analysis of promoter sequences to regulate close to half of the 21 hubs in the hESC-enriched protein interaction network. It has recently been shown that NF-Y binding site is rather conserved and over-represented in promoter regions of genes preferentially expressed in human and mouse pluripotent cells (58). In fact, NF-Y was down-regulated during differentiation (58). Taken all these observations together, NF-Y seems to be an important sustaining factor for the maintenance of hESCs by regulating its hub targets in the hESC-enriched protein interaction network (Fig. 5). In line with this, NF-Y also influences hematopoietic stem cell (HSC) self-renewal and differentiation (59).

Functional categories such as gene ontology terms (GO term) for genes enriched under certain condition(s) can facilitate functional interpretation and derive biologically meaningful conclusions. Previous studies mainly focused on the enrichment of GO terms for selected genes/proteins, largely ignored the interactions across various functional groups. Therefore, it makes more sense to identify biological meanings by investigating enriched functional interactions with protein interaction considered. To this end, we found 66 functional interaction pairs enriched in hESCs, which formed an interaction network. Interestingly, most of these interacting pairs, particularly those formed with GO:0003677 (DNA binding), GO:0003723 (RNA binding), are involved in transcription and translation. This is consistent with the need for self-renewal and unrestrained proliferation.

Human embryonic stem cell-derived therapy renews our hope for regenerative medicine, but we must first overcome several hurdles, one of which, perhaps the biggest, is that hESC-therapies may spur tumor formation $(60,61)$. There are some apparent parallel traits such as self-renewal and differentiation capacity between stem cells and cancer cells, which prompt us to the hypothesis that tumors often arise from undifferentiated stem/progenitor cells, or cancer stem cells are derived from normal stem cells $(62,63)$. Out of the 21 hubs in the hESC-enriched protein interaction network, 14 (67\%) are involved in tumorigenesis or poor cancer prognosis. In addition, a recent study showed that an embryonic stem celllike gene expression signature (part of what we used here), potentially contributing to stem cell-like phenotypes shown by many tumors, has been found in poorly differentiated aggressive human tumors (64). These observations can expand our knowledge in hESC biology and tumor formation.
In conclusion, this study has identified an enriched protein interaction network formed by $403 \mathrm{hESC}$-over-expressed gene-coding proteins. Enriched molecular functional interaction network were also found in hESCs. The existence of these interaction networks beyond randomness suggests that they are important and very likely to be responsible for the maintenance of hESCs. The hubs governing the hESCenriched protein interaction network, such as MYC, H2AFX, RUVBL1, DDX18, CDC2, HDAC2, HIST1H4C and so on, which are possibly critical in determining the fate of hESCs, deserve more attention in future investigations. It is worth noting that some hESC-associated proteins for self-renewal and pluripotency, for instance, KLF4 (14) and possibly other factors, are missing in the hESC-enriched protein interaction network. Despite this, our findings represent a step in the right direction, on the system levels, to gain more significant biological information in stem cell research. When more data become available, it is possible to refine the network and make it more informative for studying hESCs. It is also hoped that continuous research on hESCs will speed up its therapeutic applications.

\section{Acknowledgements}

This study was supported by a grant for Key lab of Biochip Research of Guangdong Province, China (NO. 2004B60144).

\section{References}

1. Thomson JA, Itskovitz-Eldor J, Shapiro SS, et al: Embryonic stem cell lines derived from human blastocysts. Science 282 : 1145-1147, 1998.

2. Newman MB and Bakay RA: Therapeutic potentials of human embryonic stem cells in Parkinson's disease. Neurotherapeutics 5: 237-251, 2008.

3. Docherty K, Bernardo AS and Vallier L: Embryonic stem cell therapy for diabetes mellitus. Semin Cell Dev Biol 18: 827-838, 2007.

4. Siu CW, Moore JC and Li RA: Human embryonic stem cellderived cardiomyocytes for heart therapies. Cardiovasc Hematol Disord Drug Targets 7: 145-152, 2007.

5. Kang HK, Roh S, Lee G, Hong SD, Kang H and Min BM: Osteogenic potential of embryonic stem cells in tooth sockets. Int J Mol Med 21: 539-544, 2008.

6. Nichols J, Zevnik B, Anastassiadis K, et al: Formation of pluripotent stem cells in the mammalian embryo depends on the POU transcription factor Oct4. Cell 95: 379-391, 1998.

7. Chambers I, Colby D, Robertson M, et al: Functional expression cloning of Nanog, a pluripotency sustaining factor in embryonic stem cells. Cell 113: 643-655, 2003.

8. Rogers MB, Hosler BA and Gudas LJ: Specific expression of a retinoic acid-regulated, zinc-finger gene, Rex-1, in preimplantation embryos, trophoblast and spermatocytes. Development 113: 815-824, 1991 .

9. Graham V, Khudyakov J, Ellis P and Pevny L: SOX2 functions to maintain neural progenitor identity. Neuron 39: 749-765, 2003.

10. Hanna LA, Foreman RK, Tarasenko IA, Kessler DS and Labosky PA: Requirement for Foxd3 in maintaining pluripotent cells of the early mouse embryo. Genes Dev 16: 2650-2661, 2002.

11. Wuchty S, Barabasi AL and Ferdig MT: Stable evolutionary signal in a yeast protein interaction network. BMC Evol Biol 6: 8,2006 .

12. Brown KR and Jurisica I: Unequal evolutionary conservation of human protein interactions in interologous networks. Genome Biol 8: R95, 2007.

13. Kim J, Chu J, Shen X, Wang J and Orkin SH: An extended transcriptional network for pluripotency of embryonic stem cells. Cell 132: 1049-1061, 2008.

14. Jiang J, Chan YS, Loh YH, et al: A core Klf circuitry regulates self-renewal of embryonic stem cells. Nat Cell Biol 10: 353-360, 2008. 
15. Loh YH, Wu Q, Chew JL, et al: The Oct4 and Nanog transcription network regulates pluripotency in mouse embryonic stem cells. Nat Genet 38: 431-440, 2006.

16. Zhou Q, Chipperfield H, Melton DA and Wong WH: A gene regulatory network in mouse embryonic stem cells. Proc Natl Acad Sci USA 104: 16438-16443, 2007

17. Chuang HY, Lee E, Liu YT, Lee D and Ideker T: Networkbased classification of breast cancer metastasis. Mol Syst Biol 3: 140,2007

18. Hahn MW and Kern AD: Comparative genomics of centrality and essentiality in three eukaryotic protein-interaction networks. Mol Biol Evol 22: 803-806, 2005.

19. Ideker $\mathrm{T}$ and Sharan R: Protein networks in disease. Genome Res 18: 644-652, 2008.

20. Wang J, Rao S, Chu J, et al: A protein interaction network for pluripotency of embryonic stem cells. Nature 444: 364-368, 2006 .

21. Assou S, Le Carrour T, Tondeur S, et al: A meta-analysis of human embryonic stem cells transcriptome integrated into a web-based expression atlas. Stem Cells 25: 961-973, 2007.

22. Brown KR and Jurisica I: Online predicted human interaction database. Bioinformatics 21: 2076-2082, 2005.

23. Yu X, Lin J, Zack DJ and Qian J: Computational analysis of tissue-specific combinatorial gene regulation: predicting interaction between transcription factors in human tissues. Nucleic Acids Res 34: 4925-4936, 2006.

24. Liang S, Li Y, Be X, Howes S and Liu W: Detecting and profiling tissue-selective genes. Physiol Genomics 26: 158-162, 2006.

25. Shannon P, Markiel A, Ozier O, et al: Cytoscape: a software environment for integrated models of biomolecular interaction networks. Genome Res 13: 2498-2504, 2003.

26. Hosack DA, Dennis G Jr, Sherman BT, Lane HC and Lempicki RA: Identifying biological themes within lists of genes with EASE. Genome Biol 4: R70, 2003.

27. Barabasi AL and Oltvai ZN: Network biology: understanding the cell's functional organization. Nat Rev Genet 5: 101-113,2004.

28. Yu J, Vodyanik MA, Smuga-Otto K, et al: Induced pluripotent stem cell lines derived from human somatic cells. Science 318 : 1917-1920, 2007.

29. Takahashi K and Yamanaka S: Induction of pluripotent stem cells from mouse embryonic and adult fibroblast cultures by defined factors. Cell 126: 663-676, 2006

30. Boyer LA, Lee TI, Cole MF, et al: Core transcriptional regulatory circuitry in human embryonic stem cells. Cell 122 947-956, 2005

31. Fernandez PC, Frank SR, Wang L, et al: Genomic targets of the human c-Myc protein. Genes Dev 17: 1115-1129, 2003.

32. Feng Y, Lee N and Fearon ER: TIP49 regulates beta-cateninmediated neoplastic transformation and T-cell factor target gene induction via effects on chromatin remodeling. Cancer Res 63: 8726-8734, 2003.

33. Prochownik EV: c-Myc: linking transformation and genomic instability. Curr Mol Med 8: 446-458, 2008.

34. Ji P, Diederichs S, Wang W, et al: MALAT-1, a novel noncoding RNA, and thymosin beta4 predict metastasis and survival in early-stage non-small cell lung cancer. Oncogene 22: 8031-8041, 2003.

35. Dubaele S and Chene P: Cellular studies of MrDb (DDX18). Oncol Res 16: 549-556, 2007.

36. Bassing CH, Suh H, Ferguson DO, et al: Histone H2AX: a dosage-dependent suppressor of oncogenic translocations and tumors. Cell 114: 359-370, 2003

37. Malkas LH, Herbert BS, Abdel-Aziz W, et al: A cancerassociated PCNA expressed in breast cancer has implications as a potential biomarker. Proc Natl Acad Sci USA 103: 19472-19477, 2006.

38. Powers MV, Clarke PA and Workman P: Dual targeting of HSC70 and HSP72 inhibits HSP90 function and induces tumorspecific apoptosis. Cancer Cell 14: 250-262, 2008.

39. Montanaro L, Brigotti M, Clohessy J, et al: Dyskerin expression influences the level of ribosomal RNA pseudo-uridylation and telomerase RNA component in human breast cancer. J Pathol 210: 10-18, 2006.

40. Chen H, Huang Q, Dong J, Zhai DZ, Wang AD and Lan Q Overexpression of CDC2/CyclinB1 in gliomas, and CDC2 depletion inhibits proliferation of human glioma cells in vitro and in vivo. BMC Cancer 8: 29, 2008.

41. Graff JR, Konicek BW, Carter JH and Marcusson EG: Targeting the eukaryotic translation initiation factor $4 \mathrm{E}$ for cancer therapy. Cancer Res 68: 631-634, 2008
42. Killian A, Sarafan-Vasseur N, Sesboue R, et al: Contribution of the BOP1 gene, located on $8 \mathrm{q} 24$, to colorectal tumorigenesis. Genes Chromosomes Cancer 45: 874-881, 2006

43. Chang TW, Chen CC, Chen KY, Su JH, Chang JH and Chang MC: Ribosomal phosphoprotein P0 interacts with GCIP and overexpression of P0 is associated with cellular proliferation in breast and liver carcinoma cells. Oncogene 27: 332-338, 2008.

44. Zhang L, Pan X and Hershey JW: Individual overexpression of five subunits of human translation initiation factor eIF3 promotes malignant transformation of immortal fibroblast cells. J Biol Chem 282: 5790-5800, 2007.

45. Weichert W, Roske A, Gekeler V, et al: Histone deacetylases 1 2 and 3 are highly expressed in prostate cancer and HDAC2 expression is associated with shorter PSA relapse time after radical prostatectomy. Br J Cancer 98: 604-610, 2008.

46. Jeong H, Mason SP, Barabasi AL and Oltvai ZN: Lethality and centrality in protein networks. Nature 411: 41-42, 2001.

47. Said MR, Begley TJ, Oppenheim AV, Lauffenburger DA and Samson LD: Global network analysis of phenotypic effects: protein networks and toxicity modulation in Saccharomyces cerevisiae. Proc Natl Acad Sci USA 101: 18006-18011, 2004.

48. Shachar R, Ungar L, Kupiec M, Ruppin E and Sharan R: A systems-level approach to mapping the telomere length maintenance gene circuitry. Mol Syst Biol 4: 172, 2008

49. Albert R: Scale-free networks in cell biology. J Cell Sci 118 4947-4957, 2005.

50. Cartwright P, McLean C, Sheppard A, Rivett D, Jones K and Dalton S: LIF/STAT3 controls ES cell self-renewal and pluripotency by a Myc-dependent mechanism. Development 132: 885-896, 2005.

51. Andang M, Hjerling-Leffler J, Moliner A, et al: Histone H2AXdependent $\mathrm{GABA}(\mathrm{A})$ receptor regulation of stem cell proliferation. Nature 451: 460-464, 2008

52. Sun Y, Li H, Liu Y, Mattson MP, Rao MS and Zhan M Evolutionarily conserved transcriptional co-expression guiding embryonic stem cell differentiation. PLoS ONE 3: E3406, 2008.

53. Wood MA, McMahon SB and Cole MD: An ATPase/helicase complex is an essential cofactor for oncogenic transformation by c-Myc. Mol Cell 5: 321-330, 2000.

54. Qiu XB, Lin YL, Thome KC, et al: An eukaryotic RuvB-like protein (RUVBL1) essential for growth. J Biol Chem 273: 27786-27793, 1998.

55. Armstrong L, Hughes O, Yung S, et al: The role of PI3K/AKT, MAPK/ERK and NFkappabeta signalling in the maintenance of human embryonic stem cell pluripotency and viability highlighted by transcriptional profiling and functional analysis. Hum Mol Genet 15: 1894-1913, 2006.

56. Murakami M, Ichisaka T, Maeda M, et al: mTOR is essential for growth and proliferation in early mouse embryos and embryonic stem cells. Mol Cell Biol 24: 6710-6718, 2004.

57. Miyabayashi T, Teo JL, Yamamoto M, McMillan M, Nguyen C and Kahn M: Wnt/beta-catenin/CBP signaling maintains longterm murine embryonic stem cell pluripotency. Proc Natl Acad Sci USA 104: 5668-5673, 2007

58. Grskovic M, Chaivorapol C, Gaspar-Maia A, Li H and Ramalho-Santos M: Systematic identification of cis-regulatory sequences active in mouse and human embryonic stem cells. PLoS Genet 3: E145, 2007.

59. Zhu J, Zhang Y, Joe GJ, Pompetti R and Emerson SG: NF-Ya activates multiple hematopoietic stem cell (HSC) regulatory genes and promotes HSC self-renewal. Proc Natl Acad Sci USA 102: 11728-11733, 2005.

60. Hentze H, Graichen R and Colman A: Cell therapy and the safety of embryonic stem cell-derived grafts. Trends Biotechnol 25: 24-32, 2007

61. Vogel G: Cell biology. Ready or not? Human ES cells head toward the clinic. Science 308: 1534-1538, 2005.

62. Lobo NA, Shimono Y, Qian D and Clarke MF: The biology of cancer stem cells. Annu Rev Cell Dev Biol 23: 675-699, 2007.

63. Reya T, Morrison SJ, Clarke MF and Weissman IL: Stem cells, cancer, and cancer stem cells. Nature 414: 105-111, 2001.

64. Ben-Porath I, Thomson MW, Carey VJ, et al: An embryonic stem cell-like gene expression signature in poorly differentiated aggressive human tumors. Nat Genet 40: 499-507, 2008. 